\title{
Scrutinizing Interlingual and Intralingual Error: Basis for English Writing Program
}

\author{
Agbay, Noralyn G. and Reyes, Yolanda D. Ed.D. \\ Bataan Peninsula State University, Balanga Bataan 2100, Philippines
}

\begin{abstract}
How to cite this paper: Agbay, Noralyn G. and Reyes, Yolanda D. Ed.D. (2019). Scrutinizing Interlingual and Intralingual Error: Basis for English Writing Program. The Educational Review, USA, 3(10), 142-151.
\end{abstract}

http://dx.doi.org/10.26855/er.2019.10.003

*Corresponding author: Reyes, Yolanda D. Ed.D., Bataan Peninsula State University, Balanga Bataan 2100, Philippines.

\begin{abstract}
An error-free written works in expected from every English language teacher. However, writing is one of the most challenging skills in learning second language. In fact, learner's error in second language resulted from the learner's assumptions that second language and native language are formed similarly and from negative transfer within the target language which are known as Interlingual and Intralingual errors respectively (Sari, 2016). In the Philippine setting, the result of the study conducted by Magno (2014) showed that error analysis among Education, major in English students yielded errors in verb tense, structure, punctuation, choice of words, spelling and so on. In line with this, the present study aimed at identifying and classifying the writing errors of the third-year college of education, English major student which will serve as the basis for an intervention program that will hone their writing skills. In the pursue of the study, findings showed that under intralingual error, tense-related errors ranked first with $15.54 \%$ followed by fragments with $12.95 \%$ and run-on with $11.66 \%$ that were caused mainly by negative transfer which ranked first with $49.42 \%$ followed by lack of knowledge with $24.32 \%$ under interlingual errors.
\end{abstract}

\section{Keywords}

Error Analysis; Intralingual Errors; Interlingual Errors; English Writing

\section{Introduction}

Error Analysis has been the subject of interest of many scholars since the past century: Corder, 1967, 19711981 ; Richards, 1971, 1984; Richards et al. 1992 and James, 1998. It is a type of linguistic analysis that is defined as the technique of identifying, classifying and systematically interpreting the unacceptable forms produced by someone learning a foreign language using any of the principles and procedures provided by linguistics (Khansir,2012). In the field of education, specifically the aspirant English language teachers are expected to exhibit good writing skills. However, writing is one of the most challenging language skills in learning the second language. As a matter of fact, according to Brant as cited by Alinsunod J. (2014), in order to satisfy language educators on written works, language learners should obtain good grammatical structures, appropriate punctuation marks, verbs in their right tenses, pronouns in the right cases and correct spelling of words. And, to obtain all these, the skills on handwriting, spelling, vocabulary, sentence construction and paragraph writing are all necessary since these skills are considered as the "building blocks of proficient writing". More so, Brown as cited by Sari (2016), stated that it has been said that the learners' errors in the second language resulted from the learners' assumption that the second language forms are similar to the native language which refers to Interlingual errors. Whilst, the negative transfer within the target language is known as Intralingual errors. In addition, committing mistakes in writing is revisable and can be easily corrected than speaking leaving the learners with no reason to commit mistakes because it is a performance according to James as cited by Quaid and Ramamoorthy (2011). Also, writing is harder in some ways than speaking because writing must be self-contained: there is no body language or vocal emphasis as everything must be in the words themselves (Graham, 2012). 
In line with errors, Brown as cited by Sawalmesh (2013), states that there are two main categories of errors, namely, interlingual errors and intralingual errors. These errors occur among language learners be it in speaking or in writing. Al-Kresheh (2010) previously suggested that one of the Interlingual errors is literal translation which is an error that happens because students translate his first language sentence or idiomatic expression into the target language word for word. Meanwhile, Lasaten (2014) mentioned in his study that one component of Interlingual Error is the Transfer which identified Negative transfer as one of its kind. Negative transfer happens when there is no concordance between native language and target language and thus, acquisition of the new target language structure would be more difficult and errors reflecting the native language structure would be produced. More so, Intralingual Interference is another form of interlingual error which was categorized by Richard (1974) as cited by Sari (2016). He classifies the intralingual interference into:

(a) Overgeneralization which happens when a learner creates a deviant structure on the basis of his experience of other structures in the target language.

(b) Ignorance of Rule in which ignorance is specific in the sense that one is normally said to be ignorant of the structure.

(c) Incomplete Application of the Rules which happens when learner fails to apply the rules completely.

(d) False Concept Hypothesized in which learners have the faulty understanding of distinctions of the target language items that lead to false conceptualization.

On the other hand, Intralingual Errors are types of errors that are caused by the target language itself. Kaweera C. (2013) defined this error as the deviate form of language caused by conflicting information of the target language unlike those interlingual errors, which are traced to first language transfer. Accordingly, applying Linguistic Discipline to Error Analysis, Lasaten (2014) previously suggested the Taxonomy of Errors which categorizes errors as to (a) Grammatical (prepositions, articles, reported speech, singular/plural, adjectives, relative clauses, infinitives, verbs and tenses, and possessive case); (b) syntactic (coordination and conjunctions, sentence structure, nouns and pronouns, and word order, fragment and run on); (c) lexical (word choice); (d) semantic (literal translation); and (e) substance/mechanics (punctuation, capitalization and spelling). Moreover, Amara (2015) describes that these kinds of error occur during the learning process of the second language at a stage when the learners have not really acquired the knowledge. In addition, errors are also caused by the difficulty or the problem of the language itself.

In the Philippine setting, English is extensively used in commercial, governmental and educational concerns. It is used in the schools as the medium of instruction from upper elementary levels to graduate school level. According to Magno et.al. (2014), the result of error analysis conducted among teacher education students showed that even education students who are specializing in English grappled when it comes to writing error-free written works which are an essential task on their part as future English language educators. The study found out that errors in verb tenses, structure, punctuation, choice of words, spelling and so on are the most common errors. Errors were mostly intralingual and the students' errors were due to overgeneralization, false concept, and incomplete rule. In line with this result, the researcher suggested that the teacher could solve the problem by giving implicit and explicit corrective feedback and remedial teaching program.

As expected, aspirant English language teachers should be able to elicit error-free written works and be a good example to their future students. However, based on the written activity of 42 Bachelor of Secondary Education, third-year English major students, none of them got an error-free essay. In basic writing skills, the result of the preliminary assessment of their papers shows the following errors: 72 incorrect punctuations; 45 incorrect letter cases; 22 incorrect spellings. In linguistics skills, the preliminary assessment of their papers shows the following errors: 136 inappropriate words; 71 inappropriate phrases; 16 incorrect pronouns; 42 incorrect prepositions; 108 incorrect tenses. More so, 92 shows the problematic organization of thoughts in their essay and there are 66 run-ons and 32 fragments that need to be corrected over a total of 702 combined errors of the 42 essays.

Since, writing among English Language teacher, plays a significant role in the field of education, this study is a response to meet the expectations among aspirant English language teachers. The study specifically aims to (1) identify the errors which the third year College of Education students major in English at Bataan Peninsula State University commit to writing English papers through computer aided and human error analysis; (2) classify and quantify common errors into interlingual errors and intralingual errors through unstructured interviews and document analysis and gain thorough 
understanding of the linguistic topics that upper-intermediate English language learners find challenging and (3) be able to contribute to the institution by providing basis for an intervention program that will help both teachers and students to better hone English writing skills.

\subsection{Statement of the Problem}

Hence the general problem of this study is: What are the interlingual and intralingual errors of the respondents in writing English papers?

Specifically, the study seeks answers the following questions:

1. What language errors are found in the composition of the respondents?

2. How may the errors be classified and quantified in terms of:

\subsection{Interlingual Errors and}

\subsection{Intralingual Errors?}

3. What are the language intervention programs can be drawn to better hone English writing skills?

\subsection{Theoretical Framework}

In the field of identifying and classifying errors in language, there are several known theories. Truly in the last decades, there had been varied theories rooted from other theories that deal with errors in the target language learning and one of which is the Error Analysis Theory, the theory to which the study is anchored. It rooted from the Contrastive Analysis which was first formulated by Charles Fries (1945) in his book Teaching and Learning English as foreign language and was further developed by Richard Lado in his book Linguistic Across Culture (1957) which is now known as Contrastive Analysis Hypothesis which states that: the more similar the target language from native language is, the easier it is for one to learn the target error which yields lesser errors. Basically, it is behaviorist and psychological in nature which was later known as the contrastive approach to error analysis. It deals with habituation which is said to be caused by interferences or transfer of the native language to the target language. Howbeit, due to lack of empirical validity which is defined as "the lack of well-defined and broadly-accepted criteria for establishing which grammatical utterances are the result of language transfer", a nativist in nature approach led to a non-contrastive approach to error analysis. This alternative approach was brought about by Noam Chomsky (1959) in his book Review of Skinner's Verbal Behavior. This had led to two different disciplines in conducting an Error Analysis:

First, the Linguistic Discipline, a Non-Contrastive Approach to Error Analysis which deals with the errors in the target language identified according to the linguistic features of the target language - the Intralingual Error. This was stated by Stephen Pit Corder (1967) in his book The significance of learner's errors.

Second, the Psycho-linguistic Discipline, a Contrastive Approach to Error Analysis which deals with the source of errors that happens between native and target language or the Interferences-Interlingual Error. This was later on identified as Interlingual Error also known as Theory of Transfer, Transfer Errors or Interlanguage Error Theory. The term 'transfer' was first used by Selinker (1969). The term transfer is a general term describing the carryover of previous performance or knowledge to subsequent learning

\subsection{Related Literature and Studies}

Congruently, Zheng and Park (2013) also had conducted a study utilizing error analysis on the errors in English writing made by Chinese and Korean students. The study analyzed the errors found in English essays written by the students, the results showed that errors made by these two groups of writers were various. They had problems in using articles and punctuation marks and ordering words. The study had identified that the negative transfer of the subjects' first language was the major source of the errors. Furthermore, Sermsook et.al. (2016) undertook the Error Analysis on Written English Sentences of 26 second year English major students in Thailand wherein 104 pieces of the participants' written work were collected showed that Intralingual interference is the major source causing the most errors, 206 errors out of 296 errors. Another study that utilized Error Analysis was conducted by Chelli as cited by Sari (2016), showed that $79.15 \%$ of the errors are made in the preposition and $72.85 \%$ in articles were caused by the negative transfer of the Arabic language. 
Meanwhile, In the study conducted by Quaid and Ramamoorthy (2011), the result showed that a total of 501 common errors were found and categorized into intralingual errors namely: fragment; the structure of the sentence and selection of words. More so, in the study of Tabatabai as cited by Heydari and Bagheri (2012) proposed that the 891 errors detected in his study were dispersed among 10 major categories such as mistakes with articles, prepositions, incorrect and confusing tenses, number, conjunctions, adjectives, subjects and predicates, verb phrases, and pronouns. The data for his research were drawn from 32 compositions written by 20 Iranian students who were in various fields of science and engineering at the States University of New York at Buffalo. He finally reported that the causes of errors that he reported were mostly intralingual. Whilst, Meanwhile, the data in the study conducted by Sari (2016) were the students' erroneous sentences in narrative writing. The sentences were taken from 90 pieces of Junior High School, Vocation high school, and University students' narrative writing. The result of the study shows that most of the errors committed by the students in junior high school (69.74\%), Vocation high school (64.22\%), University (90.21\%) are on intralingual. The data were analyzed by using the error analysis. The types of intralingual errors made by Junior High school are: (1) omission of suffix (-ed) in regular verb past consist of 8 cases $(6.78 \%)$, (2) the use of present BE in past event consist of 12 cases (14.28\%), (3) Addition of BE in past verbal sentence consist of 15 cases (12.60\%), (4) the use of present verb in past event consist of 16 cases (13.44\%), (5) wrong selection of personal pronoun consist of 5 cases (4.21\%), (6) the use of present auxiliary verb in past event consists of 6 cases $(5.05 \%)$, (7) omission of ('s) as possessive marker consist of 7 cases (5.88\%) and (8) additional of ' $S$ ' in irregular plural noun consist of 9 cases $(7.56 \%)$. The types of intralingual errors found in Vocation High School are: (1) wrong word spelling consists of 5 cases $(4.59 \%)$, (2) the use of present BE in past event consists of 24 cases $(22.02 \%)$, (3) the use of present verb in past event consists of 34 cases $(31.19 \%)$, (4) omission of s/es in regular plural noun consists of 7 cases $(6.42 \%)$. The types of intralingual errors found in University are: (1) omission of suffix (-ed) in regular verb past consist of 12 cases (14.63\%), (2) the use of present $\mathrm{BE}$ in past event consist of 20 cases $(24.40 \%)$, (3) the use of present verb in past event consist of 36 cases (39.14\%), and (4) wrong selection of pronoun consist of 5 cases $(6.10 \%)$. In the same sense, these studies showed different causes and subcategories of the intralingual errors which is also one of the aims of the present study. These findings broaden the concept of intralingual errors which were very relevant to the present study.

\subsection{Conceptual Framework}

The researcher used input-process-output paradigm in conducting the research. The study is driven to propose an intervention program that can better hone English writing skills which will be based from the identified and classified errors of the respondents. Illustration 1 provides a general overview on how the study will be conducted. The input part includes: data or the written essays of the sample; the identified written errors which will be the basis for the unstructured interview and the information that will be gathered from the unstructured interview. On the process part, it includes: the error analysis on the data; the unstructured interview with the sample respondents based from the identified written errors; the classification of errors into interlingual and intralingual errors based from the information obtain from the unstructured interview; the unstructured interview for the confirmation of the classified interlingual and intralingual errors and the validation of the error analysis. Lastly, the initial output which is an intervention program that will be based from the validated error analysis will be formulated and this initial output will then be validated by the validators to become the final output of the present study.

\section{Illustration 1.}

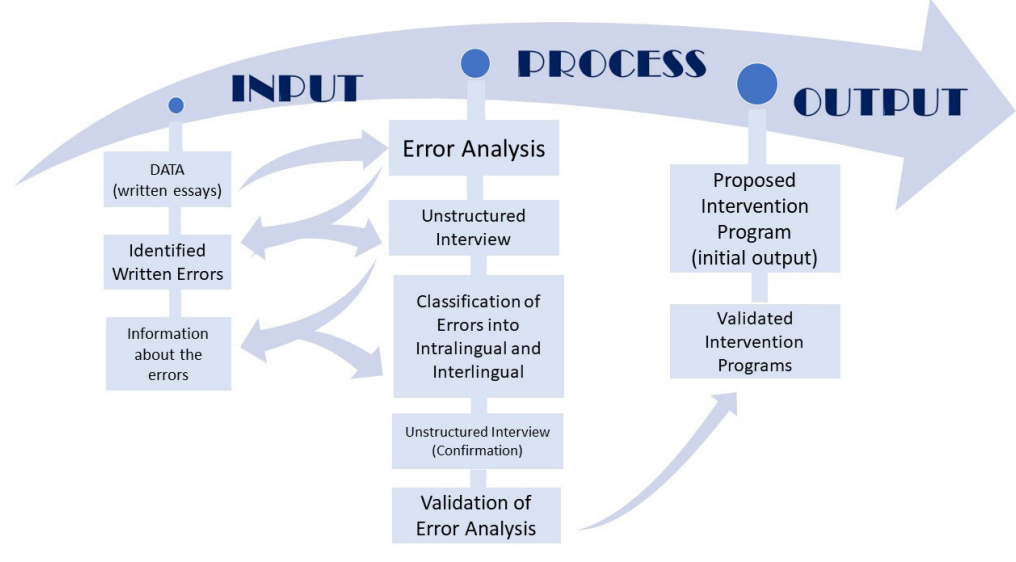




\section{Methods and Techniques of the Study}

Descriptive-Evaluative research is the classification of the present study based on the information it provides and its objective. Accordingly, descriptive research provides information about condition, situations, and events that occur in the present while evaluative is the scientific process of collecting and analyzing information about the quality, effectiveness, and value of educational programs and practices to guide decision-making on teaching and learning (Olubia, 2017). The method used was qualitative which collects and analyze non-numerical, narrative and visually observed data about the problem as stated by Olubia, (2017). Although the result was quantified, the study only used the descriptive statistic such as frequency and percentage.

For the document analysis technique, an application software, Grammarly was used to detect errors from the written essays. To check the correctness of the error analysis done by Grammarly software, human error analysis was also conducted. Also, an unstructured interview was utilized in order to further classify the identified errors into interlingual and intralingual errors. Another unstructured interview was utilized after the classification of the errors to ensure the correctness of the interpretation done by the researchers.

\subsection{Population and Sampling Size}

The population of the respondent consists of 42 third-year English major students. Since the present study was urged by the first-hand experiences of the researchers who are presently third-year students, the third-year is considered as the most suitable respondent for the said study.

The researchers employed non-probability technique specifically purposive or deliberate sampling technique in selecting both the sampling size \& the group of error-analysis validators. According to Olubia (2017), purposive or judgment sampling technique is a deliberate sampling technique where the researchers select particular group or groups based on certain criteria or purposes or variables. It is a sample selected by a researcher which in his judgment is a representative sample. Using purposive sampling technique, the selected respondents were those students who had the enormous amount of errors in their essay. Using descriptive statistics, specifically frequency and percentage, the researchers was able to identify the respondents who yielded the greatest number of errors in their essay.

\subsection{Data Gatherings and Procedures}

Primarily, the researchers sought permission from the college dean to conduct the study. Then, the researcher asked the professors in Principles of Teaching 2 and Stylistics to have a copy of the written essays of the students. Also, the researchers asked permission from the students to use their written essays thru informed consent letter. The written essays of the respondents have undergone preliminary error analysis thru human error analysis. The result showed that none of the written essays is perfectly written. From the 42 written essays that have undergone preliminary error analysis, the researcher used descriptive statistics such as percentage and frequency to reflect the result in figure. Also, the researcher employed purposive sampling technique in which the researchers decided for the sample using the following criteria: (a) the essay that consists the greatest number of errors and (b) the essay that consists of all types of error. The sample written essays have undergone error analysis using Grammarly software. The researchers classified the errors into Interlingual and Intralingual errors based from the unstructured interview. Then, the experts validated the errors. Lastly, an intervention program was formulated.

\subsection{Results and Discussions}

This chapter presents, analyzes, and interprets essential data gathered through the processes utilized in the present study. These were tabulated, analyzed and interpreted accordingly.

Table 1 shows the identified language errors found in the essays. It also shows the rank, frequency and percentage. The result shows that tense-related error yielded the greatest number of errors which is 60 while, preposition ranked fourth with 42 followed by subject-verb-agreement-number with 40. These result under grammatical feature supported the claims of Brant as cited by Alinsunod J. (2014) that in order to satisfy language educators on written works, language learners should obtain good grammatical structures since these are considered as the "building blocks of proficient writing".

More so, the preposition is one of the most difficult aspects of English grammar to master, "they account for a substantial proportion of all grammatical errors by English language students" as mentioned by Chodorow, Tetreault \& Han as cited by Lasaten, (2014). Comparably, errors related to prepositions were accounted $29 \%$ in the study conducted 
by Lasaten (2014) while the result shows that incorrect preposition is in the fourth place which is accounted for $10.88 \%$ in the presented study.

Table 1. Identified Language Errors

\begin{tabular}{|c|c|c|c|c|c|}
\hline \multicolumn{6}{|c|}{ Linguistic Feature } \\
\hline Grammatical & Rank & POT2 & Stylistics & Frequency & Percentage \\
\hline Preposition & $4^{\text {th }}$ & 26 & 16 & 42 & 10.88 \\
\hline Articles & $7^{\text {th }}$ & 18 & 11 & 29 & 7.51 \\
\hline Tense & $1^{\text {st }}$ & 36 & 24 & 60 & 15.54 \\
\hline Verb Form & $8^{\text {th }}$ & 12 & 13 & 25 & 6.48 \\
\hline SV-Number & $5^{\text {th }}$ & 23 & 17 & 40 & 10.36 \\
\hline \multicolumn{6}{|l|}{ Lexical } \\
\hline Word Choice & $6^{\text {th }}$ & 26 & 10 & 36 & 9.33 \\
\hline \multicolumn{6}{|l|}{ Syntactic } \\
\hline Run on & $3^{\text {rd }}$ & 33 & 12 & 45 & 11.66 \\
\hline Fragments & $2^{\text {nd }}$ & 29 & 21 & 50 & 12.95 \\
\hline \multicolumn{6}{|l|}{ Mechanics } \\
\hline Punctuation & $6^{\text {th }}$ & 22 & 14 & 36 & 9.33 \\
\hline Spelling & $10^{\text {th }}$ & 3 & 1 & 4 & 1.04 \\
\hline Letter Case & $9^{\text {th }}$ & 10 & 9 & 19 & 4.92 \\
\hline \multicolumn{4}{|l|}{ Total } & 386 & 100.00 \\
\hline
\end{tabular}

In addition, similar intralingual errors namely: fragments and selection of words or word choice found and categorized in the study conducted by Qaid and Ramamoorthy (2011) were also found in the present study where fragments yielded 50 which ranked as second most common error and word choice yielded 36 which ranked as the sixth most common errors. Whilst, in the study conducted by Sari (2016), the tense-related error also yielded a significant number at the university level which is accounted for a total of $68.17 \%$. Similarly, in the present study tense-related errors yielded the most number of errors which is accounted for $15.54 \%$. Congruently, the explosion of social media that brought cyber slang as stated by Tomaszweski (2011) undeniably damages students' writings skills in a way that people nowadays forget even the correct spelling of words. Errors in spelling yielded 1.04\% or 4 cases. According to interview, wrong spelling is attributed to the habit of shortening the words in text, chats and other social media communications coupled with false conception in the English language.

Significantly, the result shows that in the area of English grammar, tense requires ample attention in learning the English language. Errors in Run-on and Fragments are also crucial, based on the identified interlingual errors which will be discussed in the table below. These Intralingual errors were resulted from ignorance of the rule due to complexity of the target language itself as being argued by Celce-Murcia (2014) by stating that mastering grammar is a complex process that requires "making series of decisions when and why to use one form rather than the other" which is also evident in the verb form error which yielded $6.48 \%$ and the Negative Transfer.

Table 2 a shows the classification of errors into intralingual errors and their corresponding sources of errors or interlingual errors. The result shows that Tense-related error is caused by both Lack of knowledge and negative transfer. Lack of knowledge is having no enough knowledge or no knowledge at all in the specific linguistic feature. While, the 
negative transfer is the difference between two languages.

Table 2a. Classification of Errors

\begin{tabular}{|l|l|}
\hline (2.1) Intralingual Errors & (2.2) Interlingual Errors \\
\hline Grammatical & \multicolumn{2}{|l|}{} \\
\hline Preposition & False concept \\
\hline Articles & False concept \\
\hline \multirow{2}{*}{ Tense } & Lack of knowledge \\
\cline { 2 - 3 } & Negative Transfer \\
\hline Verb Form & Lack of knowledge \\
\hline \multirow{2}{*}{ SV-Number } & Lack of knowledge \\
\cline { 2 - 3 } & Overgeneralization \\
\cline { 2 - 2 } & Negative Transfer \\
\hline \multirow{2}{*}{ Lexical } & \multicolumn{2}{|l}{} \\
\hline Word Choice & Literal Translation \\
\hline Syntactic & \multicolumn{2}{|l}{} \\
\hline Run on & Negative Transfer \\
\hline Fragments & Negative Transfer \\
\hline Mechanics & Negative Transfer \\
\hline Punctuation & False concept \\
\cline { 2 - 2 } Spelling & Overgeneralization \\
\hline \multirow{2}{*}{ Letter Case } & Negative Transfer \\
\hline
\end{tabular}

In the case of tense, in the mother-tongue of the respondents, they only have three tenses, the past, the present and the future. While, in the target language, there are 3 main tenses, the simple, the perfect aspect and the progressive aspect. Since, there is a big difference between the construction and usage of tenses between two languages, respondents found it difficult to apply and acquire the target language causing them to commit errors in their essays.

Table 2b. Quantification of Errors

\begin{tabular}{|l|c|c|c|}
\hline Interlingual Errors & Rank & Frequency & Percentage \\
\hline Negative Transfer & $1^{\text {st }}$ & 254 & 49.42 \\
\hline Lack of Knowledge & $2^{\text {nd }}$ & 125 & 24.32 \\
\hline False Concept & $3^{\text {rd }}$ & 75 & 14.59 \\
\hline Literal Translation & $4^{\text {th }}$ & 36 & 7 \\
\hline Overgeneralization & $5^{\text {th }}$ & 24 & 4.67 \\
\hline Total & & $\mathbf{5 1 4}$ & $\mathbf{1 0 0}$ \\
\hline
\end{tabular}


Table 2b. cont.

\begin{tabular}{|c|c|c|c|}
\hline Intralingual Errors & \multirow{2}{*}{ Rank } & \multirow{2}{*}{ Frequency } & \multirow{2}{*}{ Percentage } \\
\hline Grammatical & & & \\
\hline Preposition & $4^{\text {th }}$ & 42 & 10.88 \\
\hline Articles & $7^{\text {th }}$ & 29 & 7.51 \\
\hline Tense & $1^{\text {st }}$ & 60 & 15.54 \\
\hline Verb Form & $8^{\text {th }}$ & 25 & 6.48 \\
\hline SV-Number & $5^{\text {th }}$ & 40 & 10.36 \\
\hline \multicolumn{4}{|l|}{ Lexical } \\
\hline Word Choice & $6^{\text {th }}$ & 36 & 9.33 \\
\hline \multicolumn{4}{|l|}{ Syntactic } \\
\hline Run on & $3^{\text {rd }}$ & 45 & 11.66 \\
\hline Fragments & $2^{\text {nd }}$ & 50 & 12.95 \\
\hline \multicolumn{4}{|l|}{ Mechanics } \\
\hline Punctuation & $6^{\text {th }}$ & 36 & 9.33 \\
\hline Spelling & $10^{\text {th }}$ & 4 & 1.04 \\
\hline Letter Case & $9^{\text {th }}$ & 19 & 4.92 \\
\hline Total & & 386 & 100 \\
\hline
\end{tabular}

Table $2 \mathrm{~b}$ shows the rank, frequency, and percentage of both intralingual and interlingual errors. Interlingual errors are said to be the sources of the errors between mother tongue and target language. The classification of this errors was cross-checked between empirical evidence found in the intralingual errors and the information gathered from the unstructured interviews conducted with the respondents.

The result shows that negative transfer ranked first in the present study which was classified by Lasaten (2014) in his study yielded $49.42 \%$ or 254 out of 514 total cases of errors. Accordingly, negative transfer refers to errors because an old habitual behavior is different from that to be learned or the difference between MT and TL. Similar to the study conducted by Zheng and Park (2013), the result of their study shows the error such as articles and punctuation marks were due to negative transfer. In the same sense, Chelli as cited by Sari (2016), showed that 79.15\% of the errors made in the preposition and $72.85 \%$ in articles were caused by negative transfer.

Next is the Lack of Knowledge due to the complexity of the TL itself. Lack of knowledge yielded $24.32 \%$ and is ranked as the second most common error. Another is the false concept which refers to a faulty understanding of the distinctions of the target language yielded $14.59 \%$ and is ranked as the third most common error. These errors were classified as sub-categories under intralingual interference which was categorized by Richard (1974) as cited by Sari (2016). Then, the literal translation error which was categorized by Al-Khresheh (2010) in his study which happens whenever the students translate MT to TL word-for-word. It yielded 7.00\% and it ranked the least error. And lastly, the overgeneralization which yielded $4.67 \%$ or 24 out of 514 interlingual errors.

In the Intralingual Errors, most common errors found were the (a) tense-related while, second to the least common errors were (b) wrong spelling. In Essay \#36: But during my highschool days everything was change we are allowed to speak English everytime we recite/answer. Evidently, 'highschool' and 'everytime' were misspelled. The reason for this, according to the interview, false conception is the interlingual error that causes incorrect spelling. For the word 'highschool', the respondent does not know that these words should be written separately. According to him/her, what $\mathrm{s} /$ he knew is that: this word is spelled this way. On the other hand, overgeneralization is the reason for the misspelled 'everytime'. The respondent applied the same rule of constructing words such as to everyone, everywhere, everything, and so on. 
While, 'was change' is a tense-related error which is in passive voice so, 'change' should be in its past participle form, 'changed'. Hence, it was incorrectly structured. According to the interview, s/he admitted that s/he only knows a little when it comes to passive voice and that $\mathrm{s} / \mathrm{he}$ was not sure if $\mathrm{s} / \mathrm{he}$ will use present tense or simple past tense or past participle tense of the verb and so, this reason also contributes to interlingual error which is lack of knowledge.

Empirically, this error was due to another interlingual error aside from lack of knowledge which is classified as (1) negative transfer. In Filipino grammar, the sentences are usually ordered into clauses with a verb in the simple past or present tense only. It is acceptable to use either of the two simple tenses provided that there is consistency throughout the narration. Also, simple tenses are the dominant tenses in lengthy discourse in Filipino which greatly influenced the writings of the respondents because this is not the case in English. Tenses used were tossed among perfect aspects and progressive aspects in the English Language. This difference between MT and LT made it more difficult for the Filipino to avoid committing errors in tenses.

Another intralingual error that was classified due to negative transfer and overgeneralization was (c) subject-verbagreement-number since, in Filipino, we only add 'mga' in our Filipino nouns and it does not affect our verb. Take a look at this example:

$$
\begin{array}{ll}
\text { Tumakbo ang mga aso. [plural] } & \text { The dogs run [plural] } \\
\text { Tumakbo ang aso. [singular] } & \text { The dog runs [singular] }
\end{array}
$$

In the example above, the verb 'tumakbo' has no relation to or agreement with the number of the noun 'aso' unlike in English sentences. Example of this error was present in Essay \#7, She never give up in teaching me. that's why I'm so grateful to have her. The subject in this sentence is 'she' which is singular hence, requires singular verb which is 'gives'. Aside from negative transfer, (2) overgeneralization was also one of the causes of this error. Overgeneralizing the rule for the noun in which, there is no ' $\mathrm{s}$ ' if it is singular.

The next set of intralingual errors were: (d) punctuation; (e) fragments; (f) run-on and (g) letter case. These were all associated with the negative transfer. Punctuation errors were mainly because of the fillers that are frequently used in Filipino narratives. Many are conscious that, instead of using punctuation, they use fillers. Fillers are: 'ahhm', 'hmmm', 'kasi...', 'ano...'. Although 'kasi' and 'ano' are words with grammatical function in Filipino, they are commonly used as fillers. In addition to fillers, the use of tentative language or Hedges in Filipino is very common. Hedges in Filipino are: 'parang', mukhang' and others. These are cautious notes which express fuzziness, hesitation, and uncertainty in cases where the writers lack convictions to a given statement. This negative transfer manifests when the Filipino writer use hedges counterparts such as: 'seems', 'thinks', 'like' and others. In example Essay \#37: In that, we developed a good skills in speaking English language and that's the reason why I love and like to take English as my major even I knew that it will become quite difficult for me, but nothing is impossible right? Aside from the error in 'a good skills' which is supposedly 'good skills' only, run on is evident in this sentence because it lacks proper punctuation. In this example, the student overused conjunction, as if the modality is verbal.

Another sentence from Essay \#37: I could not even barely remember, how did I really learn to speak in my first language which is Filipino and the second is English. 'the second is English' is an example of fragmented clause because it has no clear identification of the subject in it. The correction made for this sentence is: I could not even barely remember how I learn to speak in my first language which is Filipino and in my second language which is English. Negative transfer is also the reason behind this error. According to the information gathered from the author of this essay, S/he writes whatever comes into his/her mind in Filipino as if s/he is talking then writes it directly in English. In Essay \#18: My family is not the only reason why i learned my first language. Error in letter case is evident and this is because of negative transfer. The pronoun 'I' in English should always be capitalized. In contrary, 'Ako' in Filipino is not always capitalized.

These errors play a significant role since these are the identified sources of errors in the writings of the respondents. Being able to identify these interlingual errors among the respondents allow the researchers to formulate an intervention that will address these errors, thus, honing their writing skills in the English language.

\section{Summary of Findings}

The classified and quantified language errors or Intralingual Errors found were: (a) Grammatical such as preposition 
[rank $4^{\text {th }}$ with $1.088 \%$ ] ; articles [rank $7^{\text {th }}$ with $7.51 \%$ ]; tense [rank1 with $15.54 \%$ ]; verb form [rank $8^{\text {th }}$ with $6.48 \%$ ] and subject-verb agreement [rank $5^{\text {th }}$ with 10.36]; (b) Lexical which refers to word choice [rank $6^{\text {th }}$ with $9.33 \%$ ]; (c) Syntactic such as run on [rank $3^{\text {rd }}$ with $11.66 \%$ ] and fragments [rank $2^{\text {nd }}$ with $12.95 \%$ ]; (d) Mechanics which includes punctuation [rank $6^{\text {th }}$ with $9.33 \%$ ], spelling [rank $10^{\text {th }}$ with $1.04 \%$ ] and letter case [rank $9^{\text {th }}$ with $4.92 \%$ ].

The classified and quantified interlingual errors were: (a) negative transfer which rank $1^{\text {st }}$ with $49.42 \%$; (b) lack of knowledge which rank $2^{\text {nd }}$ with $24.32 \%$; (c) false concept which rank $3^{\text {rd }}$ with $14.59 \%$; (d) literal translation which rank $4^{\text {th }}$ with $7 \%$ and (e) overgeneralization which rank $5^{\text {th }}$ with $4.67 \%$.

Intralingual Errors and Interlingual Errors were found interrelated with one another among the respondents. Most of their intralingual errors were due to interlingual errors. More so, according to the information gathered from the interviews, respondents were not aware of these kinds of errors, hence, causing them to continuously repeat the same errors whenever they write in the English language.

The result of the error analysis was validated and this serves as the basis for the formulation of an intervention program. The initially formulated intervention program was also validated in order to ensure the appropriateness and the correctness of its content.

\section{Conclusion}

Based on the findings, the need to respond on the cases of students' error both interlingual and intralingual which may cause them academic setbacks; failure to elicit error-free written works and failure to become role model for their future students is called for an intervention program to address the identified and classified errors among the respondents and to better hone their writing skills in the English Language. The formulated intervention program specifically designed for the Third Year English Major students of Bachelor of Secondary Education at Bataan Peninsula State University S.Y. 2017-2018 which is a 3-day writing work-shop was validated by expert Professors in English Language of the Bataan Peninsula State University. Thus, ensuring the correctness and the appropriateness of the said intervention program to really serve its purpose.

\section{Recommendation}

Implementation of the formulated intervention program is highly recommended.

Further studies on the effectiveness of the formulated intervention program are highly recommended.

Also, inclusion of essay writing during placement assessment of the incoming English major students is highly recommended.

Comprehensive discussion of the evaluated errors of the students during oral diagnostic in English is also highly recommended.

Lastly, one of the limitations of this study is its generalizability since, the present study is exclusive only to the thirdyear level and to the English major students. Thus, replication of the said study to other year-levels and other fields of specialization is highly recommended. 